Research Paper

\title{
Phosphoinositide specific phospholipase Cyl inhibition- driven autophagy caused cell death in human lung adenocarcinoma A549 cells in vivo and in vitro
}

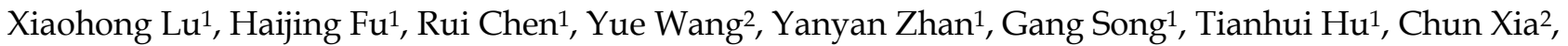 \\ Xuemei Tian ${ }^{3 凶}$, Bing Zhang ${ }^{1 凶}$ \\ 1. Cancer Research Center, School of Medicine, Xiamen University, 361102, Fujian, China \\ 2. Zhongshan Hospital, Xiamen University,361004, Xiamen, Fujian, China \\ 3. School of Life Sciences, South China Normal University, 510631, Guangzhou, Gangdong, China \\ $\bowtie$ Corresponding authors: E-mail address: tianxuemei@m.scnu.edu.cn (Xuemei Tian), cristal66@xmu.edu.cn (Bing Zhang)
}

(1) The author(s). This is an open access article distributed under the terms of the Creative Commons Attribution License (https://creativecommons.org/licenses/by/4.0/). See http://ivyspring.com/terms for full terms and conditions.

Received: 2019.12.11; Accepted: 2020.02.03; Published: 2020.02.21

\begin{abstract}
Our previous studies indicated that phosphoinositide specific phospholipase CYl (PLCYl) was involved in autophagy induction in colon and hepatic carcinoma cells. However, whether and how PLCYl regulation in human lung adenocarcinoma is linked to autophagy remains unclear. Here, we assessed the protein expression of PLCYl in human lung adenocarcinoma tissue using immunohistochemistry assay and the relationship between PLCGI and autophagy in The Cancer Genome Atlas Network (TCGA) using Spearman correlation analysis and GSEA software. Furthermore, the interaction between PLCYl and autophagy-related signal molecules was investigated in human lung adenocarcinoma A549 cells treated with different inhibitors or transduction with lentivirus-mediated PLCYl gene short-hairpin RNA (shRNA) vectors using MTT, clonogenicity, Transwell migration, RT-PCR, Caspase-3, mitochondrial transmembrane potential, and western blotting assays, as well as transmission electron microscope technique. Additionally, the effect of shRNA/PLCYl alone or combined with autophagic activator Lithium Chloride $(\mathrm{LiCl})$ on tumor growth and metastasis was measured using immunohistochemistry and assays in A549 xenograft nude mouse model. The results showed that increased PLCY1 expression occurred frequently in human lung adenocarcinoma tissue with higher grades of T in TNM staging classification. PLCYl significantly enriched in autophagic process and regulation, which negatively regulating autophagy was enriched in higher expression of PLCY1. PLCY1 inhibition partially reduced cell proliferation and migration of $A 549$ cells, with an increased autophagic flux involving alterations of AMPKa, mTOR, and ERK levels. However, PLCYl inhibition-driven autophagy led to cell death without depending on Caspase- 3 and RIP1. Additionally, the abrogation of PLCYl signaling by shRNA and combination with autophagic activator $\mathrm{LiCl}$ could efficaciously suppress tumor growth and metastasis in A549 xenograft nude mice, in combination with a decrease in P62 level. These findings collectively suggest that reduction of cell proliferation and migration by PLCYl inhibition could be partially attributed to PLCY1 inhibition-driven autophagic cell death (ACD). It highlights the potential role of a combination between targeting PLCYl and autophagy pathway in anti-tumor therapy, which may be an efficacious new strategy to overcome the autophagy addition of tumor and acquired resistance to current therapy.
\end{abstract}

Key words: PLC 11 inhibition, autophagic cell death (ACD), lung adenocarcinoma A549 cells, A549 xenograft nude mice

\section{Introduction}

Macroautophagy (afterwards referred to as autophagy) could serve as a cytoprotective mechanism in response to various pathological status and stress, including tumor [1-4]. At the early stage of tumor, autophagy links to suppression of tumor development; autophagy actuates progression and 
therapy resistance by maintaining cellular homeostasis in fully evolved tumors [2,3]. Hence, autophagy is a double-edged sword in tumor process [4]. Although targeting autophagy could be a promising therapeutic approach for tumor treatment through blocking development, preventing therapy resistance, and improving clinical outcome [5], treating patients with autophagy inhibitors or enhancers limits on experimental stage with an unfavorable outcome $[3,6.7]$. It may be associated with the ambiguous biological mechanism of how autophagy affects tumor initiation, progression, and therapy [6].

Phosphoinositide specific phospholipase $C_{\gamma} 1$ (PLC $\gamma 1$ ) plays an important role in regulating cell proliferation and migration of tumor [8-10]. Very recent study reports that PLCG1 could act as an oncogene in hepatocellular carcinoma carcinogenesis and may serve as a valuable prognostic marker and potential therapeutic target for hepatocellular carcinoma [11]. Some studies have addressed the existence of a link between PLCY and autophagy. Both IP3 and DAG (two hydrolysis products of PIP2 by PLC $Y$ activity) are involved in regulating autophagy [12-14]. Additionally, in primary human keratinocytes, PLCY is the FGFR2b substrate, which acts as an upstream regulator of both phagocytosis and autophagy [15]. Our previous study also demonstrated that PLC $\gamma 1$ inhibition could induce autophagy in HCT116 and HepG2 cells [16]. Hence, there exists a link between PLC $\gamma 1$ and autophagy in tumor progression.

Lung adenocarcinoma is $40 \%$ of total lung cancer cases, which has a 5-year survival rate of only $15 \%$ [17]. PLC $\gamma 1$ as one of oncogenic HER2 downstream signaling mediators is hyper-activated in HER2H878Y driven lung tumors [18]; PLC $\gamma$ is associated with bulk migration of non-small cell lung carcinomas [19]. Recently, Zahra Timsah et al reported that expression pattern of PLC $\gamma 1$ acts as a novel prognostic marker of recurrence-free survival in lung adenocarcinoma [20]. Therefore, it is conceivable that PLC $\gamma 1$ participates in regulating cell metabolism of lung carcinoma. However, whether and how PLC $\gamma 1$ regulation is linked to autophagy has not been determined in human lung adenocarcinoma.

In this study, we investigated the effect of PLC $\gamma 1$ inhibition on cell proliferation and migration and its regulatory mechanism linked to autophagy in human lung adenocarcinoma A549 cells. Furthermore, the effect of shRNA/PLC $\gamma 1$ alone and combination with autophagy activator Lithium Chloride $(\mathrm{LiCl})$ on tumor growth and metastasis was evaluated in A549 xenograft nude mouse model. Our studies demonstrated that PLC 1 inhibition-driven autophagy led to autophagic cell death (ACD), which might partially take responsibility for the reduction of cell proliferation and migration by PLC $\gamma 1$ inhibition. This highlights a potential role of the combination of targeting PLC $Y 1$ and autophagy pathway in antitumor therapy.

\section{Results}

\section{PLCY 1 inhibition reduced cell proliferation and migration in human adenocarcinoma A549 cells}

PLC 1 expression in human lung adenocarcinoma was assessed by immunohistochemistry assay in a tissue microarray. The majority $(78.57 \%)$ of human lung adenocarcinoma specimens (T2, T3) showed a specific immune reactivity to PLC $\gamma 1$ (Fig.1, Table $1, \mathrm{p}=0.003<0.05)$. Although the percentage of higher expression of PLC 1 in human lung adenocarcinoma specimens with regional lymph node metastasis (N1, N2, 73.91\%) was more than that in non-metastatic specimens (N0,48.48\%), there was no significance between them, maybe due to the smaller number of samples in the tissue microarray (Table 1, $\mathrm{p}=0.057>0.05)$. As a result, increased PLC $\gamma 1$ expression occurred frequently in human lung adenocarcinoma tissue with higher grades of $\mathrm{T}$ in TNM staging classification. Meanwhile, human lung adenocarcinoma A549 cells were treated with PLC $\gamma 1$ inhibitor U73122 (U), following the detection of cell viability and migration. Treatment of $U$ significantly reduced cell viability and colony formation (Fig. 2A, ${ }^{* *} \mathrm{p}<0.01$, vs untreated group). The mRNA level of MMP2 and MMP9 and number of migrate cells decreased significantly in A549 cells in response to U (Fig.2B, ${ }^{*} p<0.05,{ }^{* * *} p<0.001$, vs untreated group). Similarly, the depletion of PLC 1 with lentiviralmediated shRNA/PLC $11-1 / 2$ (shPLC $11-1 / 2$ ) vectors caused a reduction of cell proliferation and migration (Fig.2C\&D, ${ }^{* * *} p<0.001,{ }^{* * * *} p<0.0001$, vs con77 group). Taken together, the data indicated that increased PLC 1 expression occurred frequently in human lung adenocarcinoma tissue with higher grades of $\mathrm{T}$ in TNM staging classification and that PLC $\gamma 1$ inhibition reduced cell proliferation and migration in human lung adenocarcinoma A549 cells.

Table 1. Clinical pathological characteristics of PLCY1 in human lung adenocarcinoma

\begin{tabular}{llllll}
\hline & \multicolumn{2}{l}{ PLC1 } & & & \\
\cline { 2 - 6 } & Cases & $-/++$ & $\mathbf{+ + / + + +}$ & $\mathbf{X ~}^{\mathbf{2}}$ & $\mathbf{P}$ \\
\hline Tumor stage & 28 & 17 & 11 & 8.93 & 0.003 \\
I & 28 & 6 & 22 & & \\
II, III & & & & & \\
Metastasis & 33 & 17 & 16 & 3.6 & 0.057 \\
Non-metastasis & 23 & 6 & 17 & & \\
Regional lymph node metastasis & 23 & & & &
\end{tabular}




\section{PLCY 1 inhibition promoted autophagic flux in human lung adenocarcinoma A549 cells}

The relationship between PLC $\gamma 1$ and autophagy was firstly assessed in The Cancer Genome Atlas Network (TCGA) by Spearman correlation analysis and GSEA software. Integrative and comparative genomic analysis of human lung adenocarcinoma demonstrated that PLC $\gamma 1$ significantly enriched in autophagic process and regulation, which negatively regulating autophagy was enriched in higher expression of PLC 1 (Fig. 3A, r $\leq-0.4, p<0.001$ ). Furthermore, the expression level of autophagic markers, including LC3B and P62, was measured via western blotting analysis in A549 cells in response to U. Fig.3B showed that treatment of $U$ led to an increase in LC3B-II level in combination with a decrease in P62 level, implying that $U$ increased autophagic flux. Similar results were observed in A549 cells transduced with shPLC 1 1-1/2 vectors (Fig. 3C, Left panel). The increased LC3B-II level by shPLC $\gamma 1-1 / 2$ vectors was reversed by transfection with pRK5-PLC $\gamma 1$ vectors (Fig. 3C, Right panel). Especially, addition of Chloroquine (CQ, autophagy inhibitor) interrupted the execution of PLC 1 inhibitor on LC3B-II and P62 protein expression (Fig.3D\&E). In addition, under a transmission electron microscope, autophagic vacuoles (red arrows) increased obviously without chromatin condensation and oncosis in A549 cells transduced with shPLC $11-2$ vector (Fig.3F). Overall, PLC $\gamma 1$ inhibition using either
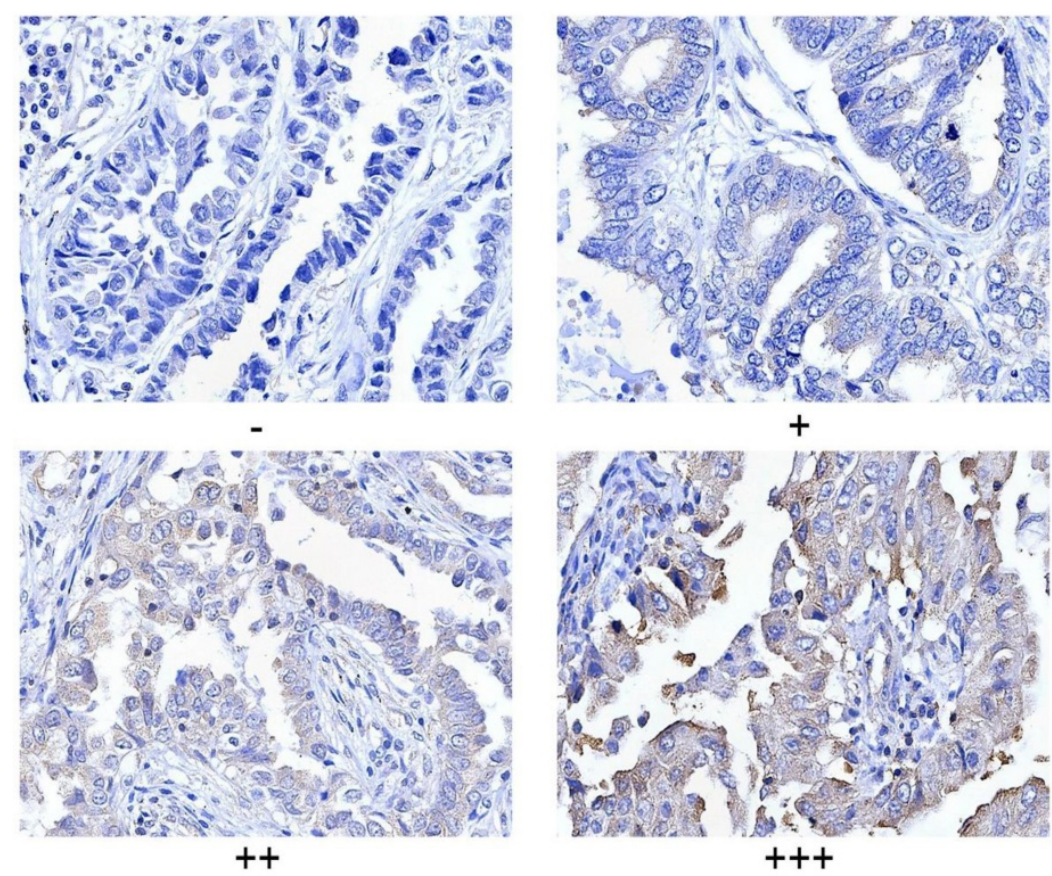

Figure 1. Criteria for statistical analysis of PLCY1 expression in human adenocarcinoma. PLCYl expression was detected in the tissue microassay with immunohistochemical assay as described in the Material and methods section (original magnification $\times 40$ ).
shRNA vector or inhibitor promoted autophagic flux in A549 cells.

\section{Involvement of AMPKa, mTOR, and ERK signal molecules in PLCY1 inhibition-driven autophagy in human lung adenocarcinoma A549 cells}

Fig. 4A displayed that treatment with $\mathrm{U}$ elevated the phosphorylation of AMPKa at Thr172 site (p-AMPKa) in A549 cells. Transduction with shPLC $\gamma 1-1$ vector has the same effect on p-AMPKa (Fig. 4B). In contrast, the phosphorylation of mTOR at Ser2448 site (p-mTOR), ULK1 at Ser757 site (p-ULK1), and ERK at Thr202/Tyr204 site (p-ERK) was interrupted by treatment with $\mathrm{U}$ or transduction with shPLC 1 1-1 vector (Fig.4A, 4B).

To further confirm the relationship between AMPKa, mTOR, and ERK in PLC $\gamma 1$ inhibition-driven autophagy, A549 cells were treated with different activator and inhibitor, or transfected with different expressing vectors. Fig. $4 \mathrm{C}$ showed that both $\mathrm{p}-\mathrm{PLC} \gamma 1$ and p-FAK levels significantly decreased in A549 cells in response to $5 \mathrm{mM}$ metformin (an AMPKa activator). Similarly, transfection with p3xFLAG-CMV10AMPKa1 (AMPKa1) vector expressing AMPKa1 and p3xFLAG-CMV10-AMPKa2 (AMPKa2) vector expressing AMPKa2 caused an observable decrease in p-PLC $\gamma 1$ and p-FAK levels (Fig.4D). Thus, AMPK might act upstream of PLC $\gamma 1$ and FAK to execute its function in A549 cells. Meanwhile, A549 cells transfected with $\mathrm{pRK} 5-\mathrm{HA}$-tagged $\mathrm{PLC} \gamma 1$ vector were treated with respective inhibitors of mTOR (Rapamycin) or ERK (PD98059). Fig. 4E showed that overexpressed PLC 1 elevated p-mTOR and p-ERK levels, along with a decrease in LC3B-II and an increase in P62 levels, compared with un-transfected group with pRK5HA-tagged PLC 1 vector. Compared with A549 cells transfected with pRK5-HA-tagged PLC $\gamma 1$ vector without Rapamycin or PD98059 treatment, treatment of Rapamycin partially reversed the effect of overexpressed PLC $\gamma 1$ on LC3B-II and P62 levels, such as an increase in LC3B-II and a decrease in P62 levels (Fig.4E). Treatment of PD98059 had little influence on LC3B-II and P62 levels (Fig.4E). Additionally, Rapamycin not only suppressed p-mTOR, but also reduced ERK and p-ERK levels in A549 cells overexpressing PLC $\gamma 1$. However, PD98059 had no obvious influence on p-mTOR level in A549 cells overexpressing PLC ${ }^{1} 1$ (Fig.4E). mTOR might 
be reasonably supposed to act upstream of ERK in PLC 1 1-driven autophagy of A549 cells. Therefore, AMPKa, mTOR, and ERK signals were involved in PLC $\gamma 1$ inhibition-driven autophagy in human lung adenocarcinoma A549 cells.

\section{PLCY1 inhibition-driven autophagy leads to cell death in human lung adenocarcinoma A549 cells}

Now that autophagy is a double-edged sword in tumor progression, it is necessary to confirm the effect of PLC $\gamma 1$ inhibition-driven autophagy on cell proliferation and migration of A549 cells. Fig.5A-D showed that addition of autophagy inhibitors, CQ or 3-MA, reversed the inhibitory effect of $U$ on cell proliferation and migration $\left({ }^{* * *} p<0.001,{ }^{* * * *} p<0.0001\right.$, vs U-treated group). Considering that increased autophagy in the fully evolved tumors is usually to be thought to contribute to the enhancement of drug resistance, mRNA levels of multidrug resistanceassociated protein genes (MRP1) and multidrug resistance phosphoglycoprotein ATP-binding cassette subfamily $\mathrm{B}(\mathrm{ABCB} 1)$ were detected by RT-PCR assay in A549 cells. Fig.5E showed that PLC $\gamma 1$ inhibition with treatment by $U$ or transduction with shPLC $\gamma 1-2$ vector led to decreased mRNA levels of MRP1 and ABCB1 in A549 cells, implying that PLC $\gamma 1$ inhibitiondriven autophagy did not enhance drug resistance in A549 cells ( ${ }^{* *} \mathrm{p}<0.01,{ }^{* * * *} \mathrm{p}<0.0001$, vs con77 group).

A

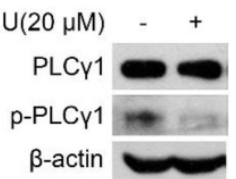

$\mathrm{B}$

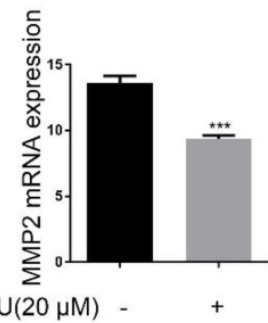

C

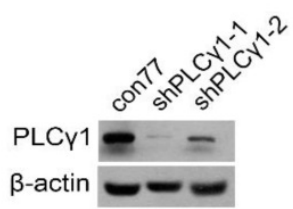

D

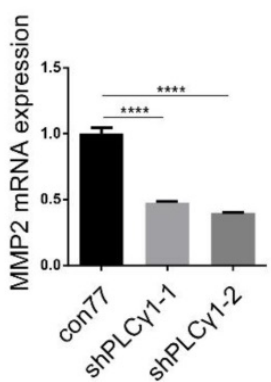

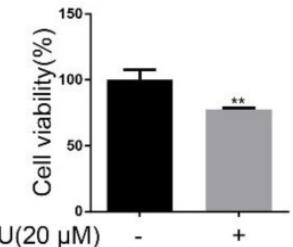
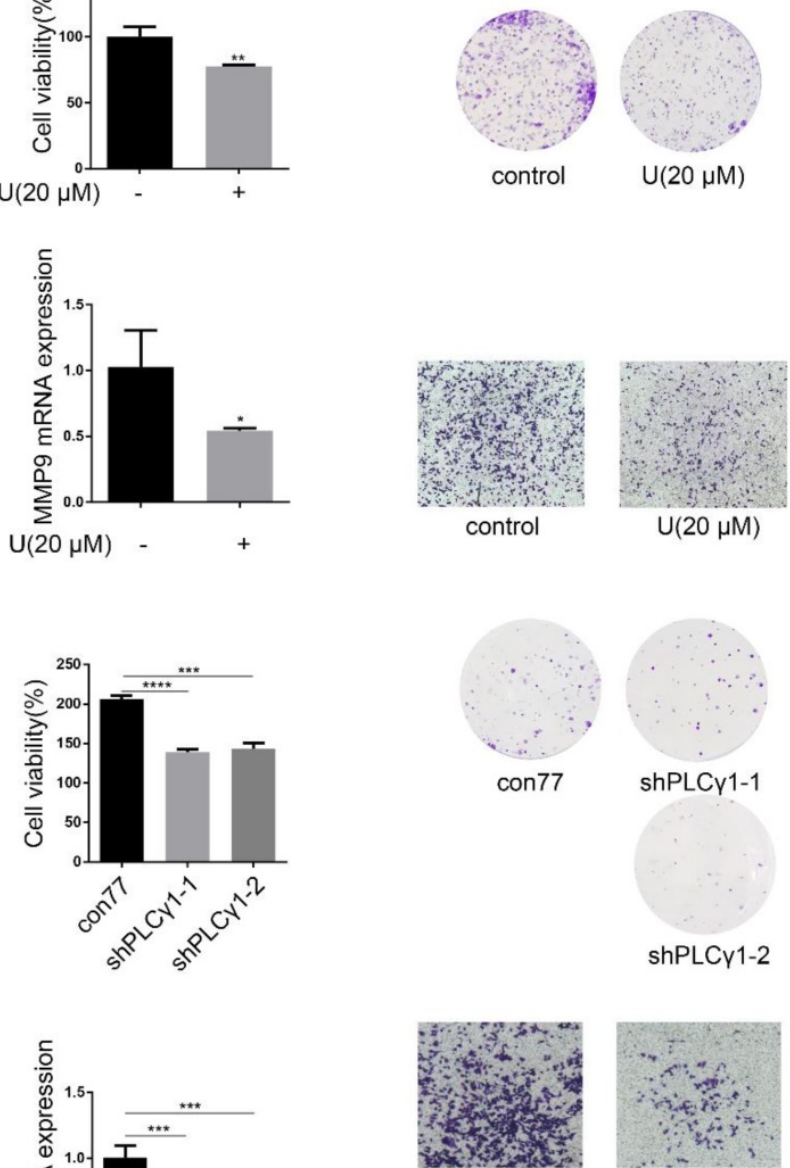

$\operatorname{con} 77$

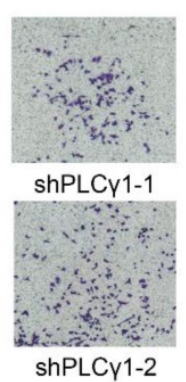

Figure 2. Effect of PLCY1 on cell proliferation and migration of human adenocarcinoma A549 cells. (A) \& (B) Cells were treated with $U$ (20 $\mu M$ ) for 24 hours. The PLCY1, P-PLCY1, and $\beta$-actin protein levels were detected via western blotting, followed with the detection of cell viability via MTT assay and cell growth via colony forming as described in the Material and methods section(A). The MMP2 and MMP9 mRNA levels were detected via RT-PCR assay and the migrated cells were observed via Transwell migration assay as described in the Material and methods section (B). (C)\&(D) Cells were transduced with shRNA/PLCY1-1/2 vectors. The PLCY1 and $\beta$-actin protein levels were detected via western blotting, followed with the detection of cell viability via MTT assay and cell growth via colony forming as described in the Material and methods section(C). The MMP2, MMP9, and GAPDH mRNA levels were detected via RT-PCR assay and the migrated cells were observed via Transwell migration assay as described in the Material and methods section (D). The data are representative of three independent experiments $\left({ }^{*} p<0.05\right.$, ** $\left.p<0.01, * * * p<0.001, * * * * p<0.0001\right)$. 
A
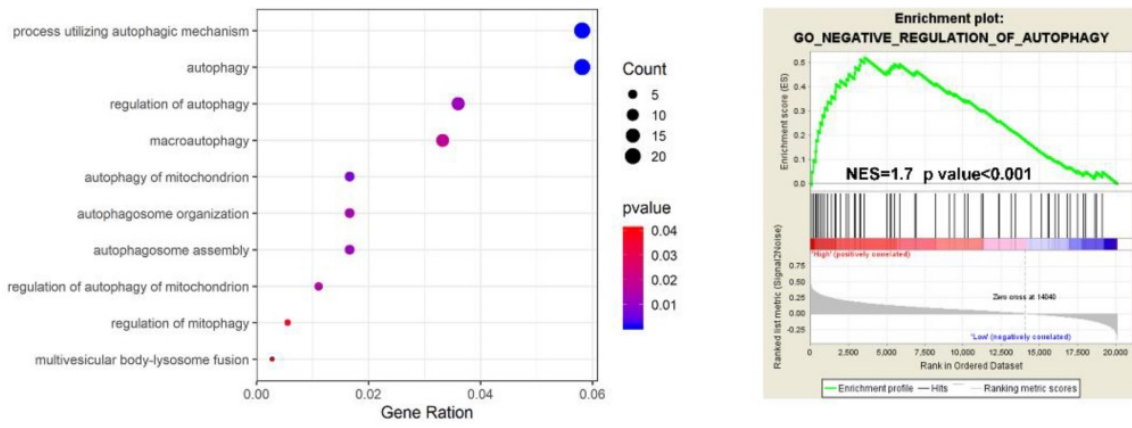

B

C
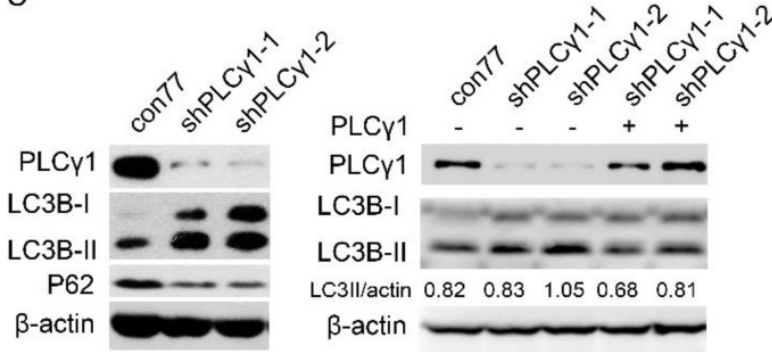

D

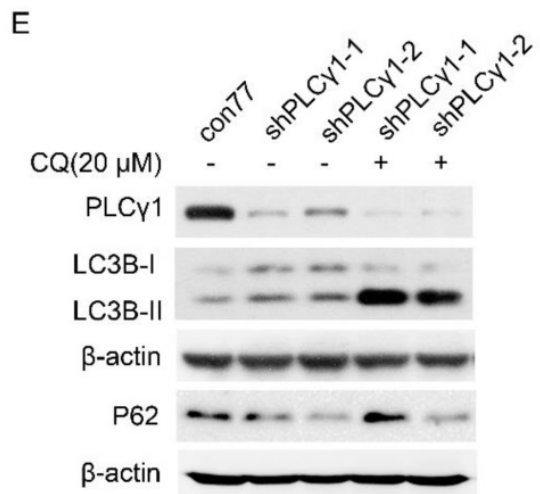

F
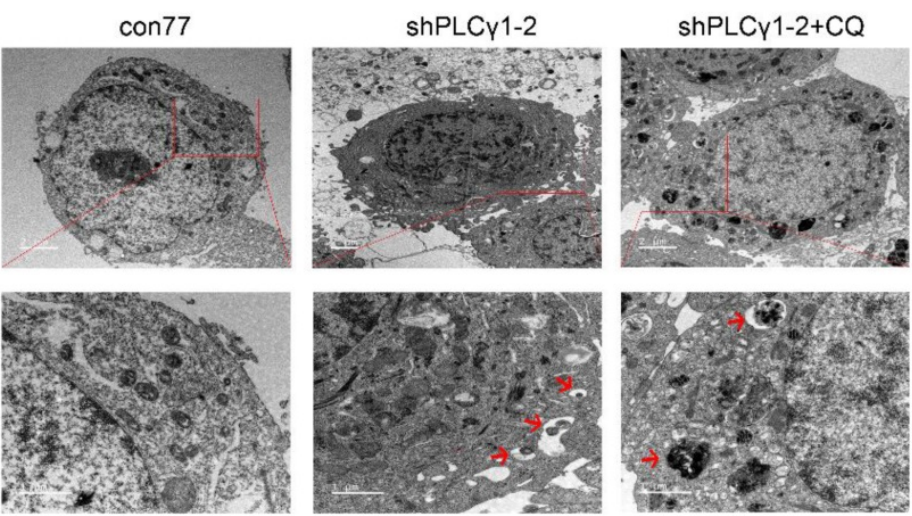

Figure 3. PLCY1 inhibition promotes autophagic flux in human adenocarcinoma A549 cells. (A) The relationship between PLCG1 and autophagy was assessed in The Cancer Genome Atlas Network (TCGA) by Spearman correlation analysis and GSEA software as described in the Material and methods section ( $r \leq-0.4$, $p<0.05)$. (B) Cells were treated with different concentrations of $U(20,30$, and $40 \mu \mathrm{M})$ for 24 hours and the PLCYl, p-PLCYl, LC3B, p62, and $\beta$-actin protein levels were detected via western blotting as described in the Material and methods section. (C) Cells were transduced with shRNA/PLCY1-1/2 vectors and the PLCY1, LC3B, p62, and $\beta$-actin protein levels were detected via western blotting as described in the Material and methods section (Left panel). Cells stably expressing shRNA/PLCYI-1/2 were transiently transfected with PRK5-PLCYl vectors, and the PLCYI, LC3B, and $\beta$-actin protein levels were detected via western blotting (Right panel). (D) Cells pretreated with CQ (20 $\mu$ M) for 1 hour were co-treated with $\mathrm{U}(20 \mu \mathrm{M})$ for 24 hours and the PLCY1, p- PLCY1, LC3B, p62, and $\beta$-actin protein levels were detected via western blotting analysis as described in the Material and methods section. (E)\&(F) Cells transduced with shRNA/PLCY1-1/2 vectors were treated with or without CQ $(20 \mu M)$ for 24 hours. The PLCY1, LC3B, p62, and $\beta$-actin protein levels were detected via western blotting as described in the Material and methods section (E). After samples were made as described in the Material and methods section and autophagic vacuoles (indicated by red arrows) were observed under a transmission electron microscope (F). The data are representative of three independent experiments. 


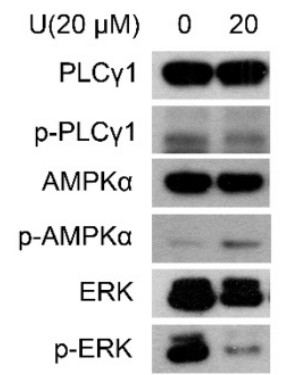

C

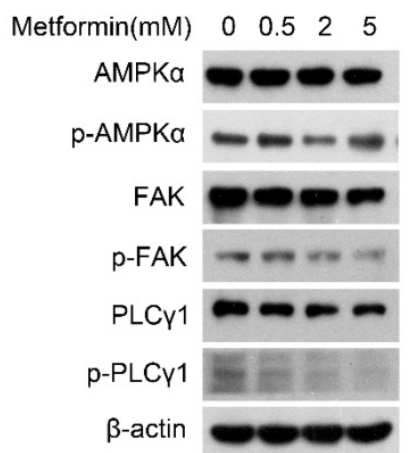

B

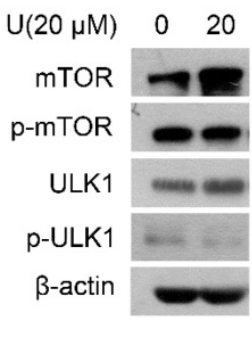

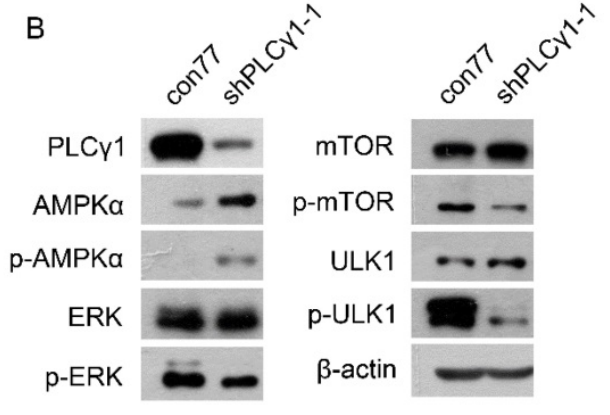

D

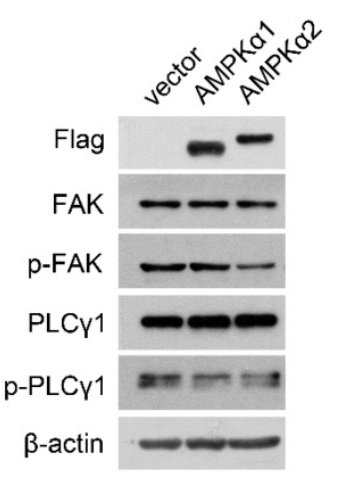

E

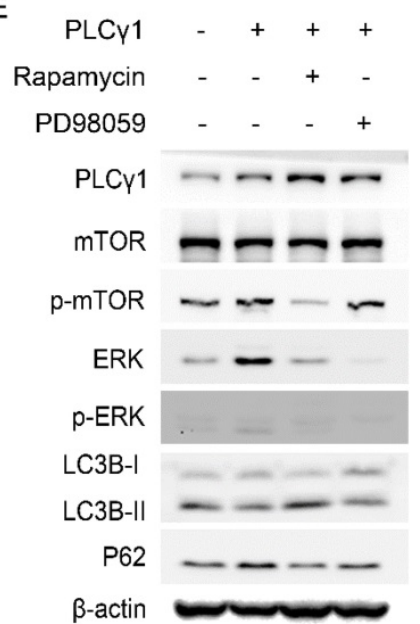

Figure 4. Involvement of AMPK, mTOR, and ERK in PLCY1 inhibition-driven autophagy in A549 cells. (A) Cells were treated with $U$ (20 $\mu M$ ) for 24 hours, and the PLCY1, p-PLCY1, AMPKa, p-AMPKa, mTOR, p-mTOR, ULK1, p-ULK1, ERK, p-ERK, and $\beta$-actin protein levels were detected via western blotting as described in the Material and methods section. (B) Cells were transduced with shRNA/PLCY1-1 vector, and the PLCY1, p-PLCY1, AMPKa, p-AMPKa, mTOR, p-mTOR, ULK1, p-ULK1, ERK, p-ERK, and $\beta$-actin protein levels were detected via western blotting as described in the Material and methods section. (C) Cells were treated with different concentrations of Metformin $(0.5,2,5 \mathrm{mM})$ for 12 hours and the PLCY1, p-PLCY1, AMPKa, p-AMPKa, FAK, p-FAK, and $\beta$-actin protein levels were detected via western blotting as described in the Material and methods section. (D) Cells were transiently transfected with AMPKal or AMPKa2 vector, and the Flag, PLCY1, p-PLCY1, FAK, p-FAK, and $\beta$-actin protein levels were detected via western blotting as described in the Material and methods section.(E) Cells transfected transiently with pRK5-PLCY1 vectors were treated with or without Rapamycin $(1 \mu \mathrm{M})$ and PD98059 $(20 \mu \mathrm{M})$ for 24 hours, respectively. The PLCY1, mTOR, P-mTOR, ERK, P-ERK, LC3B, P62, and $\beta$-actin protein levels were detected via western blotting as described in the Material and methods section. The data are representative of three independent experiments.

Programmed cell death includes three forms, autophagy cell death (ACD), apoptosis, and necroptosis, which have respective characteristics [4]. Fig.6A showed that either treatment with $U$ or transduction with shPLCY1-1/2 vectors had not any effect on Caspase-3 expression, but both led to an increase in Bcl-2 level (Fig.6A). Simultaneously, treatment of $U$ did not significantly reduce Caspase-3 activity (Doxorubicin as positive control) (Fig.6B, ${ }^{* *} \mathrm{p}<0.01$, vs control group). Furthermore, compared with control group, treatment of $\mathrm{U}$ did not lead to a decline of mitochondrial membrane potential, implying that the reduction of cell proliferation by PLCY1 inhibitor might not associated with Caspase3-dependent apoptosis (Fig.6C). Additionally, neither Caspase inhibitor (Z-VAD-FMK) nor necroptosis inhibitor (Necrostatin-1(Nec-1)) that inhibits allosterically the kinase activity of receptor-interacting protein 1 (RIP1)) treatment influenced the inhibitory effect of PLC $\gamma 1$ inhibitor on cell proliferation (Fig.6D, vs U-treated group).Especially, either Z-VAD-FMK or
Nec-1 boosted the effect of $U$ on cell migration in A549 cells (Fig.6E\&F, ****p<0.0001, vs U-treated group). These results indicated that the reduction of cell proliferation and migration by PLC $\gamma 1$ inhibitiondriven autophagy in A549 cells were different from apoptosis and necroptosis.

\section{Effect of depletion of PLCY 1 by shRNA or treatment of $\mathrm{LiCl}$ on tumor growth and metastasis in a nude mouse xenograft model of A549 cells}

To determine the role of PLC $\gamma 1$ and its link to autophagy in the therapy of lung adenocarcinoma, the status of tumor in a nude mouse model harboring tumor xenograft derived from A549 cells transduced with shPLC $1-2$ vector was evaluated. From the beginning of 30 days after subcutaneous injection of A549 cells transduction with or without shPLC $11-2$ vector, subcutaneous tumor volume in con77 group was significantly larger than the other groups (Fig.7A, $\left.{ }^{*} \mathrm{p}<0.05,{ }^{\wedge} \mathrm{p}<0.001,{ }^{\#} \mathrm{p}<0.0001\right)$. Subcutaneous tumor 
weight was reduced in shPLC $\gamma 1$ and shPLC $\gamma 1+\mathrm{LiCl}$ groups (Fig.7B, ${ }^{*} \mathrm{p}<0.05,{ }^{* * *} \mathrm{p}<0.001$, vs con77 group). However, there was no significant difference between shPLC $\gamma 1$ and shPLC $\gamma 1+\mathrm{LiCl}$ or $\mathrm{con} 77+\mathrm{LiCl}$ and shPLC $\gamma 1+\mathrm{LiCl}$ groups (Fig. 7B). Meanwhile, Fig.7C showed that accompanied with decreased PLCG1 mRNA level (Left panel, ${ }^{* *} \mathrm{p}<0.01,{ }^{* * *} \mathrm{p}<0.001$, vs con77 group), mRNA level of $\mathrm{P} 62$ in con77+LiCl, shPLC $\gamma 1$, and shPLC $\gamma 1+\mathrm{LiCl}$ groups reduced significantly (Right panel, ${ }^{* *} p<0.01,{ }^{* * *} p<0.001$, vs con77 group), but shPLC $\gamma 1$ combined with $\mathrm{LiCl}$ led to a significant increase in P62 mRNA level along with increase PLCG1 mRNA level $\left({ }^{* * *} p<0.001\right.$ in Left panel, * $\mathrm{p}<0.05$, in Right panel, vs shPLC $\gamma 1$ group). The results of immunohistochemistry assay showed that the percentage of relative positive cells expressing Ki67 in subcutaneous tumor tissue of con77 group was higher than that in con77+LiCl, shPLC $\gamma 1$, and

A

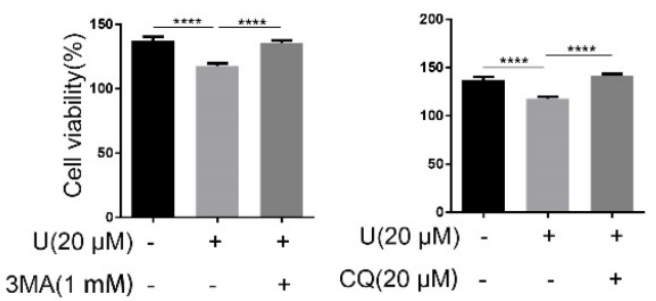

C

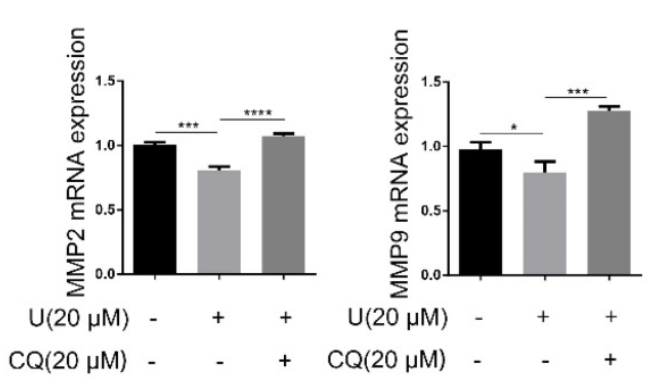

shPLC $\gamma 1+\mathrm{LiCl}$ groups (Fig.7D, $\quad * * * p<0.001$, $* * * * p 0.0001)$. Although the percentage of relative positive cells expressing $\mathrm{Ki} 67$ in shPLC $\gamma 1+\mathrm{LiCl}$ group was lower than that in con77+LiCl group, the percentage in shPLC $\gamma 1+\mathrm{LiCl}$ group was higher than that in shPLC $\gamma 1$ group (Fig.7D, * $p<0.05$ ).Like Ki67 expression in subcutaneous tumor tissue, MMP2 expression level in subcutaneous tumor tissue of con77 group was higher than that in con77+ $\mathrm{LiCl}$, shPLC $\gamma 1$, and shPLC $\gamma 1+\mathrm{LiCl}$ groups, while there was no difference between shPLC $\gamma 1$ and shPLC $\gamma 1+\mathrm{LiCl}$ groups or con $77+\mathrm{LiCl}$ and $\mathrm{shPLC} \gamma 1+\mathrm{LiCl}$ groups (Fig.7E, ${ }^{*} \mathrm{p}<0.05,{ }^{* *} \mathrm{p}<0.01$ ). Collectively, either the depletion of PLC $\gamma 1$ by shPLC $\gamma 1$ or treatment with $\mathrm{LiCl}$ could suppress human lung adenocarcinoma growth in a nude mouse xenograft model of A549 cells, but a combination of ShPLC $\gamma 1$ with $\mathrm{LiCl}$ did not exhibit more efficacious than one each alone.
B

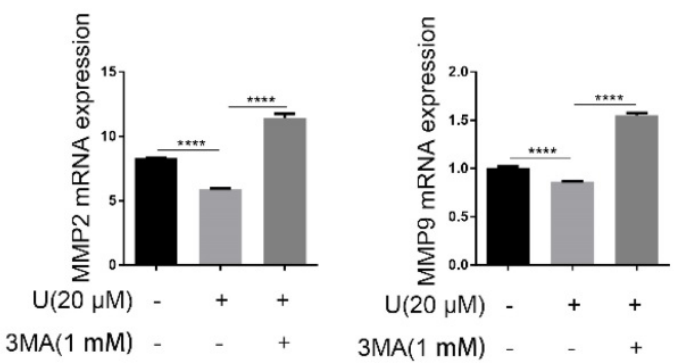

D

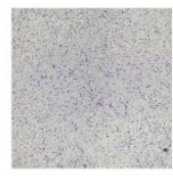

control

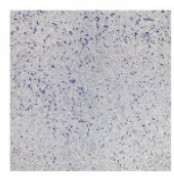

$\mathrm{U}+3 \mathrm{MA}$

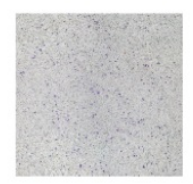

U

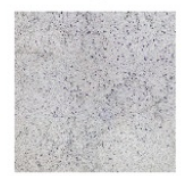

$U+C Q$

E
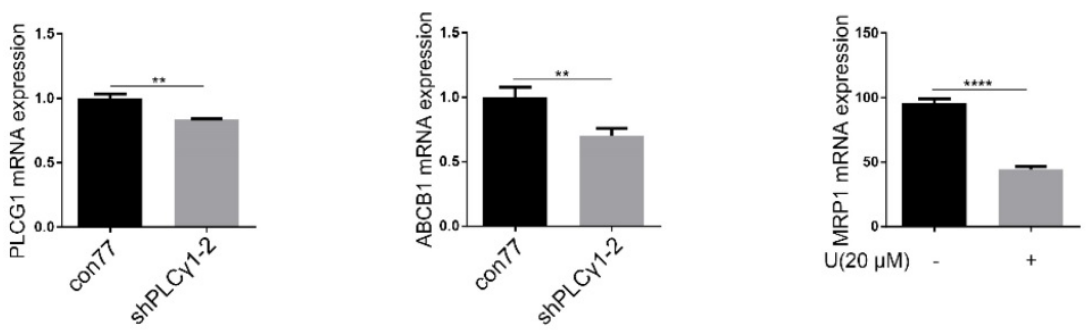

Figure 5. Effect of PLCY1 inhibition-driven autophagy on cell proliferation, migration and drug resistance in A549 cells. (A) \& (B) \& (C)\&(D) Cells were pretreated with or without $3 \mathrm{MA}(1 \mathrm{mM})$ and CQ $(20 \mu \mathrm{M})$ for 1 hour, respectively, followed by co-treatment with $\mathrm{U}(20 \mu \mathrm{M})$ for 24 hours. The cell viabilities were then detected via MTT assay as described in the Material and methods section (A). The MMP2, MMP9, and GAPDH mRNA levels were detected via RT-PCR assay as described in the Material and methods section (B\&C). The migrated cells were observed with Transwell migration assay as described in the Material and methods section (D). (E) Cells were transduced with shRNA/PLCY1-2 vectors and the PLCG1, ABCB1, MRP1, and GAPDH mRNA levels were detected via RT-PCR assay as described in the Material and methods section. The data are representative of three independent experiments $\left({ }^{*} \mathrm{p}<0.05, * * \mathrm{p}<0.01, * * * \mathrm{p}<0.001, * * * * \mathrm{p}<0.0001\right)$. 


\section{Discussion}

Autophagy not only serves as a protective mechanism to facilitate the damaged cellular constituents, but also leads to ACD [21-23]. In this study, we demonstrated that inhibition of PLC 1 promoted autophagic flux and culminated in cell death in A549 cells, in which AMPKa, mTOR, and ERK were involved. PLC $\gamma 1$ inhibition-driven ACD might contribute to the reduction of cell proliferation and migration by PLC $\gamma 1$ inhibition in A549 cells.

Here, our results that addition of CQ interrupted the alteration of LC3B and P62 caused by PLC 1 inhibition manifested the indispensible role of PLC $\gamma 1$ in enhancing autophagy flux of A549 cells. At the meantime, the data of integrative and comparative

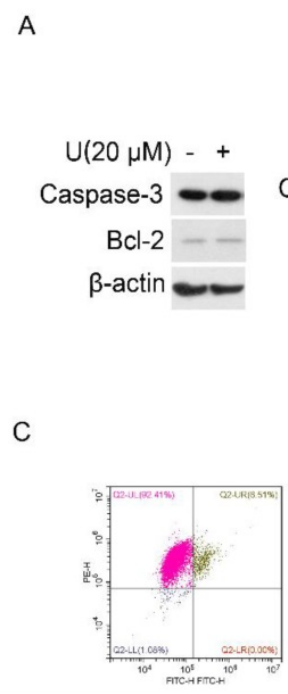

control

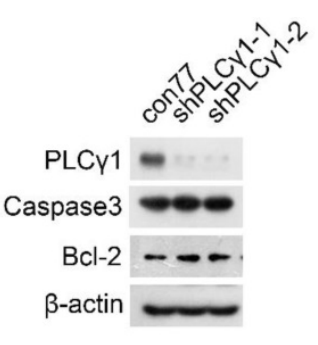

B
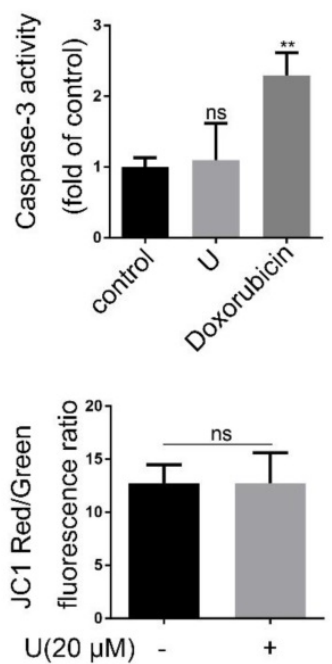

$\mathrm{U}$

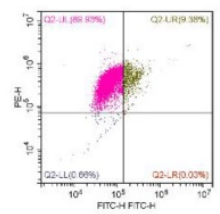

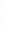

$E$

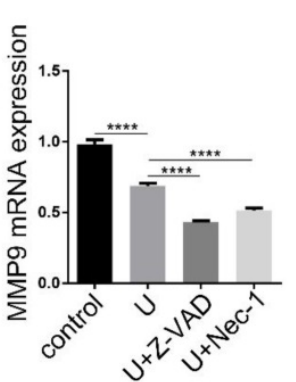

$\mathrm{F}$

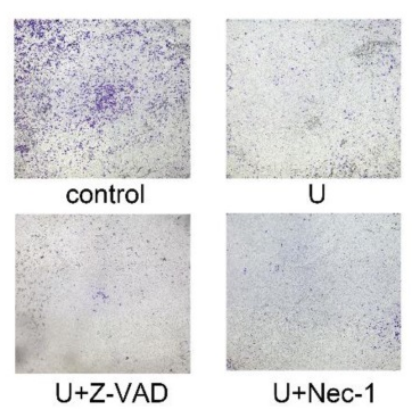

Figure 6. PLCY1 inhibition-driven autophagy lead to cell death in A549 cells. (A) Cells were treated with $U(20 \mu \mathrm{M})$ for 24 hours or transduced with shRNA/PLCY1-1/2 vectors, and the PLCYl, Caspase-3, Bcl-2, and $\beta$-actin protein levels were detected via western blotting as described in the Material and methods section. (B) Cells were treated with $U(20 \mu \mathrm{M})$ for 24 hours (Doxorubicin as positive control). Caspase-3 activity was detected as described in the Material and methods section (B). (C) Cells were treated with $U(20 \mu M)$ for 24 hours. The mitochondrial transmembrane potential was detected using JC-1 assay as described in the Material and methods section $(C)$. (D)\&(E)\&(F) Cells were pretreated with or without Z-VAD-FAK (Z-VAD,20 $\mu M)$ or Necrostatin-1 (Nec-1, $50 \mu \mathrm{M})$ for 1 hour, followed by co-treatment with $U(20 \mu \mathrm{M})$ for 24 hours. The cell viability was detected with MTT assay as described in the Material and methods section (D). The MMP9 and GAPDH mRNA levels were detected via RT-PCR assay as described in the Material and methods section (E). The migrated cells were detected via Transwell migration assay as described in the Material and methods section (F). The data are representative of three independent experiments $(* * p<0.01, * * * p<0.001$, **** $p<0.0001)$. genomic analysis of human lung adenocarcinoma also showed that the negative correlation between PLC 1 expression and autophagy regulation. Thus, it is that PLC 1 inhibition blocked mTOR and ULK1 phosphorylation in lung adenocarcinoma A549 cells, inhibition-driven autophagy. Activated ERK could regulate autophagy either positively or negatively phosphorylation has been demonstrated previously $[27,28]$. Our results that overexpression of PLC $\gamma 1$ elevated ERK level concomitant with a decrease in LC3B-II and an increase in P62 exhibited the negative regulation of PLCY1/ERK axis on autophagy in human lung adenocarcinoma A549 cells, thereby suggesting that the inhibition of PLC $1 /$ ERK axis contributed to autophagy induction in human lung adenocarcinoma A549 cells (Fig.8). In addition, we observed that activated AMPKa with treatment of metformin or transfection with AMPKa vector expressing AMPKa1 and AMPKa2 partially reduced p-FAK and p-PLC 1 levels in A549 cells, consistent with other authors' and our previous studies [16, 29-32]. Therefore, FAK and PLC $\gamma 1$ might act downstream of AMPK to regulate autophagy in A549 cells (Fig. 8). Most of evidence show that both ERK and mTOR were involved in linear signaling conduits activated by different stimuli and might intersect to regulate each other and co-regulate downstream functions [33]. Inhibition of mTORC1 leads to MAPK pathway activation through a PI3K-dependent feedback loop in human cancer [33]. mTOR pathway is involved in the post-translational regulation of the ERK phosphatase DUSP6/MKP3 [34]. IGF-1-stimulated protein synthesis in oligodendrocyte progenitors requires PI3K/mTOR/Akt and MEK/ERK pathway [35]. Here, we also found that MTOR inhibitor Rapamycin reduced ERK and p-ERK levels in A549 cells expressing PLC 1 , 
implying that activated mTOR by PLC 1 could act upstream of ERK(Fig.8). Consequently, PLC $\gamma 1$ inhibition could induce autophagy, in which PLC $\gamma 1 /$

A

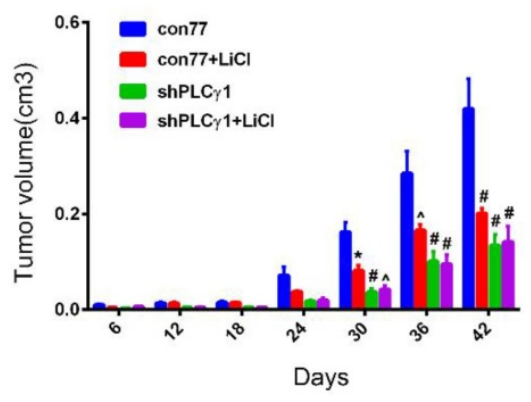

C

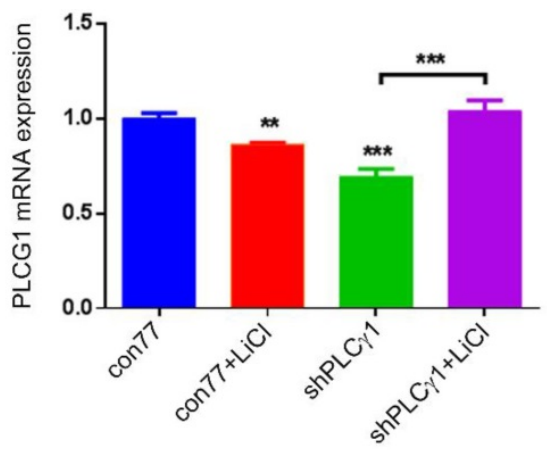

D

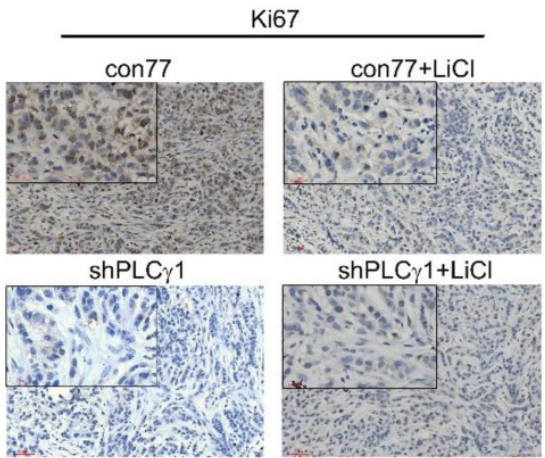

E

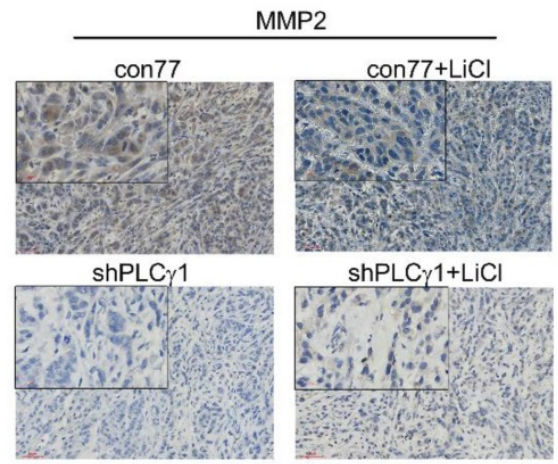

mTOR/ULK1, PLC 1 1/ERK, and AMPK-FAK/ PLC 1 axes could be involved, as well as the reciprocal regulation of ERK and mTOR (Fig.8).

B
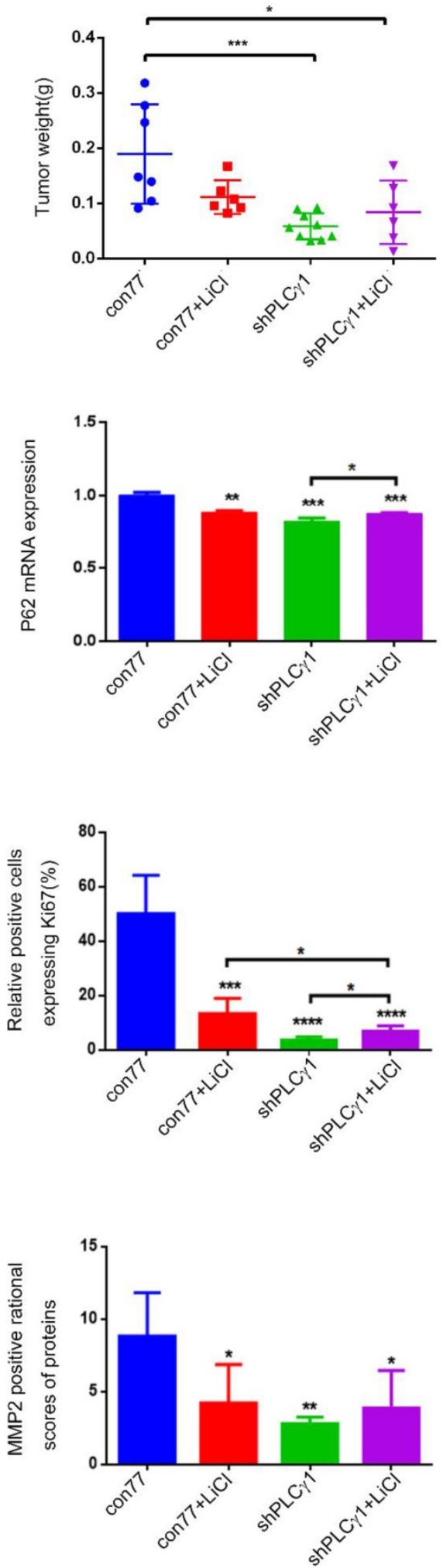

Figure 7. Effect of depletion of PLCY1 by shRNA or treatment of LiCl on tumor growth and metastasis in a nude mouse xenograft model of A549 cells. (A) Volume of tumor sample from nude mice. (B) Weight of tumor sample from nude mice. (C) Relative mRNA level of PLCG1 and P62 in tumor sample was measured using RT-PCR as described in the Material and methods section. (D)\&(E) Ki67 and MMP2 protein levels were detected via Immunohistochemistry assay as described in the Material and methods section $(* \mathrm{p}<0.05, * * \mathrm{p}<0.01, * * * \mathrm{p}<0.001, * * * * \mathrm{p}<0.0001)$. 


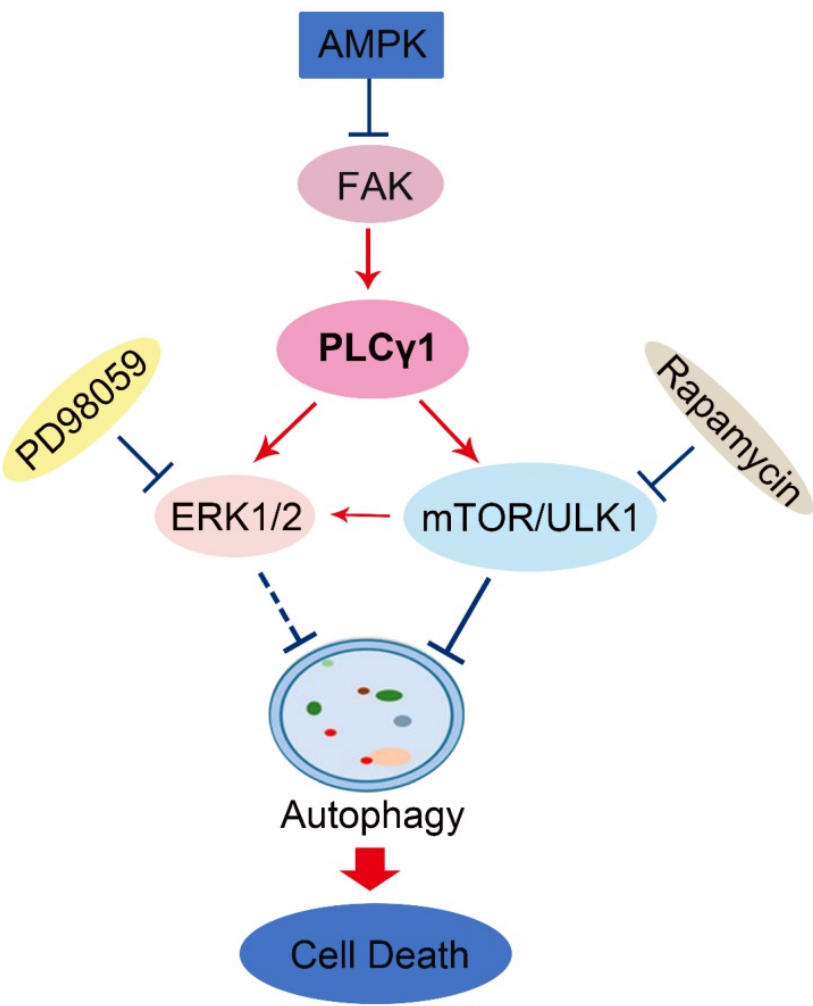

Figure 8.Schematic representation of PLCY1 inhibition-driven autophagy in human lung adenocarcinoma A549 cells.

In general, autophagy enhances cell survival and protects cell against nutrition starvation, DNA damage, and organelle damage [21]. However, prolonged or sustained autophagy may induce ACD. For example, oncogenic ras-induced expression of Noxa and Beclin-1 promotes ACD and limits clonogenic survival [22]. Isogambogenic acid induces apoptosis-independent ACD in human non-small-cell lung carcinoma cells [23]. Here, we observed that autophagy inhibitors reversed the inhibitory effect of PLC $Y 1$ inhibition on cell proliferation and migration, thereby indicating that the inhibitory effect of PLC $\gamma 1$ inhibition partially depended on PLC $\gamma 1$ inhibitiondriven autophagy. Subsequently, our results that neither Caspase-3 inhibitor (Z-VAD-FMK) nor necroptosis inhibitor (Necrostatin-1(Nec-1) treatment attenuated the inhibitory effect of PLC $\gamma 1$ inhibitor on cell proliferation and migration indicated that the reduction of cell proliferation and migration caused by PLC $\gamma 1$ inhibition-driven autophagy was independent on Caspase-3 and RIP1. Therefore, PLC $\gamma 1$ inhibition-driven autophagy might lead to ACD to reduce cell proliferation and migration in A549 cells, different from usual autophagy occurred in the fully evolved tumors. Recent studies also show that ACD is involved in some tumor therapy. For instance, plant lectins targets both apoptosis and autophagy dependent cell death in cancer therapeutics [36]. A novel triazole NMK-T-057 induces ACD in breast cancer cells by inhibiting $\gamma$-secretase-mediated activation of Notch-signaling [37]. Autophagy induced by ionizing radiation promotes cell death over survival in human colorectal cancer cells [38]. Furthermore, addition of autophagy inhibitor, $C Q$, could sensitize cancer cell to chemotherapeutic drugs $[39,40]$, then it is possible that simultaneous targeting of PLC 1 and autophagy pathway might be an efficient new strategy to overcome the autophagy addition of tumor and acquired resistance to current therapy. Disappointedly, our results in a nude mouse xenograft of A549 cells indicated that the depletion of PLC $\gamma 1$ by shPLC $\gamma 1$ could suppress human lung adenocarcinoma growth in a nude mouse tumor xenograft model, but a combination of shPLC $\gamma 1$ with autophagy activator $\mathrm{LiCl}$ did not exhibit more efficacious than one each alone. It might be due to the selection of autophagy activator or treatment dose and needs to further study.

In a summary, autophagy induced by PLC $\gamma 1$ inhibition with PLC $\gamma 1$ inhibitor or transduction with shRNA/PLC $\gamma 1$ vectors promoted ACD partially led to the reduction of cell proliferation and migration in A549 cells. PLC $\gamma 1$ might act not only upstream of mTOR and ERK, but also downstream of AMPK in PLC 1 inhibition-driven autophagy (Fig.8). A combination between targeting PLC $\gamma 1$ and autophagy pathway in anti-tumor therapy may be an efficacious new strategy to overcome the autophagy addition of tumor and acquired resistance to current therapy.

\section{Material and Methods}

\section{Antibodies and reagents}

Antibodies against PLC $\gamma 1$, p-PLC $\gamma 1$ (Tyr783), Caspase-3, AMPKa, p-AMPKa (Thr172), ERK1/2, pERK1/2 (Thr202/Tyr204), mTOR, p-mTOR (Ser2448), p-ULK1 (Ser757), FAK, and p-FAK (Tyr397) were purchased from Cell Signaling Technology Inc. (Beverly, MA, USA). Antibodies against P62, Bcl-2, and ULK1 were purchased from Abcam Inc. (Cambridge, MA, USA). Antibody against LC3B was purchased from Novus Biologicals, Inc. (Littleton, CO, USA). Goat anti-Rabbit IgG and Goat anti-Mouse IgG were purchased from Protein Tech Group (Chicago, IL, USA). The dilution concentrations of anti-Rabbit and anti-Mouse were 1:50000 and others were 1:1000. PLC $\gamma 1$ inhibitor U73122 (U), autophagy inhibitor PI3K inhibitor 3-Methyladenine (3-MA) and Chloroquine (CQ), MEK inhibitor PD98059, mTOR inhibitor Rapamycin, and AMPKa activator Metformin were purchased from Sigma-Aldrich in China (Shanghai, China). Caspase inhibitor Z-VAD-FMK (Z-VAD) and RIP1 inhibitor Necrostatin-1(Nec-1) 
were purchased from MedChemExpress USA (Monmouth Junction, NJ, USA). Antibodies against Ki67 and MMP2 were purchased from Ruiying Biological (Suzhou, China) and ABclonal (Wuhan,China) respectively. Other reagents were of the highest grade commercially available.

\section{Cell culture and treatment}

A549 cell and HEK293T cell were purchased from the Shanghai Institute of Cell Biology, Chinese Academy of Sciences (Shanghai, China). Cells were cultured with RPMI 1640 and DMEM high glucose medium (Invitrogen, Carlsbad, CA, USA), respectively, supplemented with $10 \%$ fetal bovine serum (FBS), $100 \mu \mathrm{g} / \mathrm{mL}$ streptomycin and $100 \mathrm{U} / \mathrm{mL}$ penicillin, at $37^{\circ} \mathrm{C}$ in a humidified incubator with $5 \%$ $\mathrm{CO}_{2}$. According to the different experimental requirements, cells were treated by PLC $\gamma 1$ inhibitor U73122 dissolved in N, N-Dimethylformamide (DMF) and transfected or transduced with plasmids expressing different genes, respectively.

\section{Plasmid construction and transfection}

Short hairpin RNA (shRNA) targeting PLC 1 (shPLC 1 1) was purchased from Gene Chem (Gene Chem, Shanghai, China). ShRNA sequences are shown below, shPLC $\gamma 1-1$ : 5 'C cgggcCATTGACATTC GTGAAATTctcgagATTTCACGAATGTCAATGgcTT TTTg3', shPLC 1-2: 5'CcggccAGATCAGTAACCCTG AATTctcgagAATTCAGGGTTACTGATCTggTTTTTg 3 '. After cells were tranduced with the different shPLC $\gamma 1$ vectors by a lentiviral transfection strategy, stable cell lines were obtained under the pressure of puromycin $(2 \mu \mathrm{g} / \mathrm{mL}$, BioVision, Inc., Milpitas, CA, USA). In addition, cells were transiently transfected for 24 hours with pRK5-HA-PLC $\gamma 1$ (pRK5-PLC $\gamma 1$ ) vector expressing PLC 1 , p3xFLAG-CMV10AMPKa1 (AMPKa1) vector expressing AMPKa1, p3xFLAG-CMV10-AMPKa2 (AMPKa2) vector expressing AMPKa2, using Lipofectamine 3000 (Invitrogen, Carlsbad, CA, USA), following the manufacturer's procedure and previous studies $[9,41]$.

\section{MTT assay}

Cells were seeded in 96-well plates and each well contained $100 \mu \mathrm{L}$ of complete growth medium and cultured for the indicated time. The number of viable cells were measured by 3-(4, 5-Dimethylthiazol-2-y)2,5-diphenyl-tetrazolium bromide (MTT) assay as described as previous studies $[9,42]$.

\section{Transwell migration assay}

According to the previous studies [9,43], cells in serum-free RPMI-1640 were placed into the top chambers of Transwell inserts set with $8 \mu \mathrm{m}$ pore filters and RPMI-1640 complete medium was added to the bottom chamber. After 24 hours, cells on top of the membrane were removed with a cotton swab, and then the membrane of Transwell inserts was fixed with $4 \%$ paraformaldehyde. The migrated cells on bottom of the membrane were stained with $0.1 \%$ Giemsa stain. The migrated cells were observed under an Olympus BX41 microscope equipped with a digital camera (Olympus,Tokyo, Japan) at $4 \mathrm{x}$.

\section{Colony formation assay (clonogenicity)}

As previously described [44], cells were plated in 6-well plates for indicated time. The colonies were fixed with $100 \%$ methanol and stained with $0.1 \%$ crystal violet, followed with an observation under an Olympus BX41 microscope equipped with a digital camera (Olympus,Tokyo, Japan) at $4 x$.

\section{Caspase-3 assay}

Cells were seeded in 6-well plates and treated with $\mathrm{U}(20 \mu \mathrm{M})$ or doxorubicin $(10 \mu \mathrm{M})$ for 24 hours. According to the manusfacturer's instruction of Caspase-3 activity assay kit (Beyotime Institute of Biotechnology, Haimen, China), cells were harvested and lyzed in 100ul of the cell lysis buffer included with the kit and protein concentrations were equalized for each condition. Subsequently, $50 \mu \mathrm{l}$ cell lysate was mixed with an equal amount of substrate reaction buffer containing $10 \mu$ l Caspase-3 substrate, acetyl-DEVD-p-nitroaniline (Ac-DEVD-pNA), and incubated for 4 hours at $37^{\circ} \mathrm{C}$. Samples were measured by an ELISA reader at an absorbance of 405nm (Infinite F50, TECAN, Swiss) [45].

\section{Western Blotting analysis}

Equal amounts of protein subjected to SDS-PAGE (8-15\%) were transferred to a PVDF membrane (GE Healthcare, Hertfordshire, UK) as described in previous studies $[46,47]$. The membrane was incubated with primary antibodies at $4^{\circ} \mathrm{C}$ overnight, followed by the secondary antibodies at room temperature for 1 hour. An enhanced chemiluminescence (ECL) detection kit (Pierce, Rockford, IL, USA) detected the antibody reactivity.

\section{Real-time PCR (RT-PCR) assay}

Total RNA was extracted using Trizol (Invitrogen, CA, USA) and then subjected to reverse transcription using a Primescript RT Master Mix Kit (Takara, Dalian, China) to synthesize cDNA. Real-time PCR was performed using a LightCycler (Roche) with a SYBR Premix Ex Taq II Kit (Takara, Dalian, China). Results were analyzed as described in previous studies $[41,48]$. The primers used for quantitative PCR are described in Table 2. 
Table 2. Primers in quantitative PCR

\begin{tabular}{lll}
\hline Gene & Forward Primer & Reverse Primer \\
\hline PLCG1 & $5^{\prime}$-GGAAGACCTCACGGG & $5^{\prime}$ - GCGTTTCAGGCGAA \\
& ACTTTG -3' & ATTCCA -3' \\
MMP2 & $5^{\prime}$-AGTAAACAGCAAGAGAACC & $5^{\prime}$-ACAGATGCCACAATAAAGC \\
& T -3' & $-3^{\prime}$ \\
MMP9 & $5^{\prime}$-ACTACTGTGCCTTTGAGTC -3' & $5^{\prime}$ - TACTTCCCATCCTTG \\
& & AACAA -3' \\
ABCB1 & $5^{\prime}$ - CCCATCATTGCA & $5^{\prime}$ - GTTCAA ACT \\
& ATAGCAGG -3' & TCTGCTCCTGA -3' \\
MRP1 & $5^{\prime}$-CCGTGTACTACTCCAACGCT & $5^{\prime}$-ATGCTGTGCGTGACCAAGAT \\
& GACAT -3' & CC - $3^{\prime}$ \\
P62 & $5^{\prime}$-TCCCTGTCAAGCAGTATCC-3' & $5^{\prime}$-CCTCCTTGGCTTTGTCTC-3' \\
GAPDH & $5^{\prime}$-TGCACCACCAACTGCTTAGC & $5^{\prime}$-GGCATGGACTGTGGTCATGA \\
& $-3^{\prime}$ & G -3' \\
\hline
\end{tabular}

\section{Transmission electron microscopy}

Cells were scraped and then pelleted by centrifugation at $2000 \times \mathrm{g}$ for $15 \mathrm{~min}$ at $4{ }^{\circ} \mathrm{C}$, followed by fixation for $2 \mathrm{~h}$ at $4{ }^{\circ} \mathrm{C}$ in $2.5 \%$ glutaraldehyde in 0.1 M PBS (PH7.4). After scraped and pelleted by centrifugation at $2000 \times \mathrm{g}$ for $15 \mathrm{~min}$ at $4{ }^{\circ} \mathrm{C}$, cells were fixed for 2 hours at $4{ }^{\circ} \mathrm{C}$ in $2.5 \%$ glutaraldehyde in 0.1 M PBS (pH7.4) [16,49]. Cells were dehydrated and embedded in Embed-812 resin. 70-nm sections were cut using an ultramicrotome (Leica EM UC7, LEICA, Shanghai, China) and then stained with uranyl acetate and lead citrate. Finally, autophagic vacuoles were observed under a transmission electron microscope (Tecnai G2 Spirit BioTWIN, FEI Company, Hillsboro, Oregon, USA).

\section{Immunohistochemistry assay (IHC)}

Samples from subcutaneous tumor tissue and the tissue microarray purchased from Alenabio ( $\mathrm{Xi}$ 'an, China) for immunohistochemistry assay. As described in the manufacturer's instruction (MAIXIN.BIO, Fuzhou, China), the sections were incubated overnight at $4^{\circ} \mathrm{C}$ with PLC 1 (1:100 dilutions), Ki67(1:100 dilutions), and MMP2(1:150 dilutions) primary antibody, respectively. Then the section was incubated with Diaminobenzidine (DAB) and counterstained with hematoxylin. Sections were observed under an Olympus BX41 microscope equipped with a digital camera.

PLC $\gamma 1$ and Ki67 expressions was evaluated using a semi quantitative scoring system based on staining intensity and the distribution of positive cells. The intensity of protein staining ranged from 0 to 3i.e., negative $(-)$, weak $(+)$, moderate $(++)$, and strong $(+++)$. Two pathologists were consulted for agreement and the scores were quantified by three independent observers using the criteria for statistical analysis as previously described [50,51].

\section{Mitochondrial transmembrane potential assay}

Briefly, according to the manufacturer's instruction of mitochondrial membrane potential assay kit with JC-1 (Beyotime, China), cells exposed to PLC 1 inhibitor for 24 hours were treated with JC-1. The fluorescence intensity was measured by flow cytometry (Beckman Cytoflex, USA) with FITC green channel and PE red channel [52].

\section{Identification of PLCG 1 related functions}

RNA-seq data of 586 patients diagnosed with lung adenocarcinoma from TCGA dataset were downloaded with the "TCGAbiolinks" $\mathrm{R}$ package. Significant related genes with PLCG1 expression were calculated by Spearman correlation analysis in TCGA dataset. Then, the "clusterProfiler" $\mathrm{R}$ package was used to analyze the enriched biological process of these genes ${ }^{57}$. In addition, we used GSEA (Gene Set Enrichment Analysis) software to further explore biological functions of PLCG1 in lung adenocarcinoma.

\section{A549 nude mice xenograft model}

Thirty-six 6-week-old female BALB/Cnu/nu nude mice were purchased from Shanghai Slac Laboratory Animal Co. Ltd. (Shanghai, China). All animal studies were conducted according to the regulations of the Institutional Animal Care and Use Committee protocol. This study was approved by the Committee on the Ethics of Animal Experiments of Xiamen University (No.20170196). Animals bearing tumors were randomly assigned to 2 groups (control77 and shPLC $11-2,18$ mice per group). $100 \mu \mathrm{l}$ relevant stable cells $\left(2 \times 10^{6} /\right.$ mouse $)$ in PBS were subcutaneously injected into the right foreleg of mouse [34, 46]. After 6 days post-injection of cells, each group was divided into 2 sections $(9$ mice per section), one of which was injected with $3 \mathrm{mg} / \mathrm{kg}$ body weight $\mathrm{LiCl}$ once a day for 42 days and the other was simultaneously injected with the same dose of $0.9 \%$ saline. Tumor volume and animal weight were measured every 6 days. All animals were not sacrificed until 42 days post injection. Collected tumor tissue were used for RT-PCR and immunohistochemistry assays.

\section{Statistical analysis}

Differences between the groups were examined for statistical significance using $\chi^{2}$ test with SPSS 22.0 software (IHC), Student's t-test (between two groups), and one-way ANOVA (among three groups) with GraphPad Prism 6 software. A value of $\mathrm{P}<0.05$ was considered significant.

\section{Supplementary Material}

Supplementary figures and tables. http://www.ijbs.com/v16p1427s1.zip 


\section{Acknowledgments}

This study was funded by National Natural Science Foundation of China (No. 81772533,81972091). We would like to thank MS Jiqian Xia for statistical data analytics support.

\section{Competing Interests}

The authors have declared that no competing interest exists.

\section{References}

1. Klionsky DJ \& Emr SD. Autophagy as a regulated pathway of cellular degradation. Science 2000; 290:1717-21.

2. Kimmelman AC. The dynamic nature of autophagy in cancer. Genes Dev. 2011; 25:1999-2010.

3. Classen F. Kranz P, Riffkin H, Pompsch M, Wolf A, Göpelt K, Baumann M, Baumann J, Brockmeier U, Metzen E. Autophagy induced by ionizing radiation promotes cell death over survival in human colorectal cancer cells. Exp. Cell Res. 2019;374: 29-37.

4. Shintani T. \& Klionsky D. Autophagy in Health and Disease: A Double-Edged Sword. Science. 2004; 306:990-5.

5. Sui X. Chen R, Wang Z, Huang Z, Kong N, Zhang M, Han W, Lou F, Yang J, Zhang Q, Wang X, He C, Pan H. Autophagy and chemotherapy resistance: a promising therapeutic target for cancer treatment. Cell Death Dis. 2013; 4(e): 838.

6. Levy JMM, Towers CG \& Thorburn A. Targeting autophagy in cancer. Nat. Rev. Cancer 2017;17:528-42.

7. Bortnik S \& Gorski SM. Clinical applications of autophagy proteins in cancer: from potential targets to biomarkers. Int. J. Mol. Sci. 2017;18( E):1496.

8. Lattanzio R, Marchisio M, La Sorda R, Tinari N, Falasca M, Alberti S, Miscia S, Ercolani C, Di Benedetto A, Perracchio L, Melucci E, Iacobelli S, Mottolese M, Natali PG, Piantelli M; CINBO (Consorzio Interuniversitario Nazionale per Bio-Oncologia). Overexpression of activated phospholipase $C_{\gamma} 1$ is a risk factor for distant metastases in T1-T2, N0 breast cancer patients undergoing adjuvant chemotherapy. Int J Cancer. 2013; 132:1022-31.

9. Zhang B, Zeng G, Dai L, Qian H, Hu T, Song G, Zhang B, Xia C. Metastasis of human gastric adenocarcinoma partly depends on phosphoinositide specific phospholipase $\gamma 1$ expression. Folia Histochem. Cytobiol. 2014; 52:178-86.

10. Xie Z, Chen Y, Liao EY, Jiang Y, Liu FY, Pennypacker SD..Phospholipase $\mathrm{C}$-gamma1 is required for the epidermal growth factor receptor-induced squamous cell carcinoma cell mitogenesis. Biochem. Biophys. Res. Commun.2010; 397: 296-300

11. Tang W, Zhou Y, Sun D, Dong L, Xia J, Yang B.Oncogenic role of phospholipase C- $\gamma 1$ in progression of hepatocellular carcinoma. Hepatol. Res. 2019;49: 559-69.

12. Vicencio JM, Ortiz C, Criollo A, Jones AW, Kepp O, Galluzzi L, Joza N, Vitale I, Morselli E, Tailler M, Castedo M, Maiuri MC, Molgó J, Szabadkai G, Lavandero S, Kroemer G. The inositol 1,4,5-trisphosphate receptor regulates autophagy through its interaction with Beclin 1. Cell Death Differ.2019; 16:1006-17.

13. Parys JB, Decuypere JP, \& Bultynck G. Role of the inositol 1,4,5-trisphosphate receptor/Ca2+-release channel in autophagy. Cell Commun. Signal. 2012; 10:17.

14. Shahnazari S, Yen WL, Birmingham CL, Shiu J, Namolovan A, Zheng YT, Nakayama K, Klionsky DJ, Brumell JH. A diacylglycerol-dependent signaling pathway contributes to regulation of antibacterial autophagy. Cell Host Microbe. 2010; 8:137-46.

15. Nanni M, Ranieri D, Raffa S, Torrisi MR, Belleudi F. Interplay between FGFR2b-induced autophagy and phagocytosis: role of PLC $\gamma$-mediated signalling. J Cell Mol Med.2018; 22:668-83.

16. Dai L, Chen X, Lu X, Wang F, Zhan Y, Song G, Hu T, Xia C, Zhang B. Phosphoinositide-specific phospholipase $\mathrm{C}_{\gamma} 1$ inhibition induces autophagy in human colon cancer and hepatocellular carcinoma cells. Sci.Rep.2017; 7:13912.

17. Molina JR, Yang P, Cassivi SD, Schild SE \& Adjei AA. Non-small cell lung cancer: epidemiology, risk factors, treatment, and survivorship. Mayo Clinic Proc. 2008; 83:584-94.

18. Hu Z, Hu Y, Liu X, Xi R, Zhang A, Liu D, Xie Q, Chen L. Tumor driven by gain-of-function HER2 H878Y mutant is highly sensitive to HER2 inhibitor. Oncotarget. 2015; 6:31628-39.

19. Zacharias M, Brcic L, Eidenhammer S.\& Popper H. Bulk tumour cell migration in lung carcinomas might be more common than epithelial-mesenchymal transition and be differently regulated. BMC Cancer. 2018;18: 717.

20. Timsah Z, Berrout J, Suraokar M, Behrens C, et al. Expression pattern of FGFR2, Grb2 and Plcy1 acts as a novel prognostic marker of recurrence recurrence-free survival in lung adenocarcinoma. Am J Cancer Res. 2015; 5:3135-48.

21. Shimizu S, Yoshida T, Tsujioka M, \& Arakawa S. Autophagic cell death and cancer. Int. J. Mol. Sci.2014; 15:3145-53.
22. Elgendy M, Sheridan C, Brumatti G, Martin SJ. Oncogenic Ras-induced expression of Noxa and Beclin-1 promotes autophagic cell death and limits clonogenic survival. Mol. Cell.2011; 42:23-35.

23. Yang J, Zhou Y, Cheng X, Fan Y, He S, Li S, Ye H, Xie C, Wu W, Li C, Pei H, Li L, Wei Z, Peng A, Wei Y, Li W, Chen L. Isogambogenic acid induces apoptosis-independent autophagic cell death in human non-small-cell lung carcinoma cells. Sci. Rep. 2015; 5:7697.

24. Shinojima N, Yokoyama $\mathrm{T}$, Kondo $\mathrm{Y}$, \& Kondo $\mathrm{S}$. Roles of the $\mathrm{Akt} / \mathrm{mTOR} / \mathrm{p} 70 \mathrm{~S} 6 \mathrm{~K}$ and ERK1/2 signaling pathways in curcumin-induced autophagy. Autophagy.2007; 3:635-7.

25. Yuan H, Li ZM, Shao J, Ji WX, Xia W, Lu S. FGF2/FGFR1 regulates autophagy in FGFR1-amplified non-small cell lung cancer cells. J. Exp. Clin. Cancer Res. $2017 ; 36: 72$.

26. Mendoza MC, Er EE \& Blenis J. The Ras-ERK and PI3K-mTOR pathways: cross-talk and compensation. Trends Biochem. Sci. 2011;36: 320-8.

27. Fahlman CS, Bickler PE, Sullivan B \& Gregory GA. Activation of the neuroprotective ERK signaling pathway by fructose-1,6-bisphosphate during hypoxia involves intracellular $\mathrm{Ca} 2+$ and phospholipase C. Brain Res. 2002;958:43-51.

28. Liu Z, Cai H, Zheng X, Zhang B \& Xia C. The Involvement of Mutual Inhibition of ERK and MTOR in PLCY1-Mediated MMP-13 Expression in Human Osteoarthritis Chondrocytes. Int. J. Mol. Sci. 2015; 16:17857-69.

29. Mihaylova M M \& Shaw RJ. The AMPK signalling pathway coordinates cell growth, autophagy and metabolism. Nat. Cell Biol.2011; 13:1016-23.

30. Luo M \& Guan JL. Focal adhesion kinase: a prominent determinant in breast cancer initiation, progression and metastasis. Cancer Lett. 2010; 289:127-39.

31. Arias-Del-Val J, Santo-Domingo J, García-Casas P, Alvarez-Illera P, Núñez Galindo A, Wiederkehr A, Fonteriz RI, Montero M, Alvarez J. Regulation of inositol 1,4,5-trisphosphate-induced $\mathrm{Ca} 2+$ release from the endoplasmic reticulum by AMP-activated kinase modulators. Cell Calcium. 2019; 77:68-76.

32. Hwang SL, Li X, Lu Y, Jin Y, Jeong YT, Kim YD, Lee IK, Taketomi Y4, Sato H, Cho YS, Murakami M, Chang HW. AMP-activated protein kinase negatively regulates FceRI-mediated mast cell signaling and anaphylaxis in mice. J. Allergy Clin. Immunol. 2013; 132:729-36.e12.

33. Carracedo A, Ma L, Teruya-Feldstein J, Rojo F, Salmena L, Alimonti A, Egia A, Sasaki AT, Thomas G, Kozma SC, Papa A, Nardella C, Cantley LC, Baselga J, Pandolfi PP. Inhibition of mTORC1 leads to MAPK pathway activation through a PI3K-dependent feedback loop in human cancer. J. Clin. Invest. 2008; 118:3065-74

34. Bermudez O, Marchetti S, Pagès G \& Gimond C. Post-translational regulation of the ERK phosphatase DUSP6/MKP3 by the mTOR pathway. Oncogene. 2008; 27:3685-91.

35. Bibollet-Bahena O \& Almazan G. IGF-1-stimulated protein synthesis in oligodendrocyte progenitors requires $\mathrm{PI} 3 \mathrm{~K} / \mathrm{mTOR} / \mathrm{Akt}$ and MEK/ERK pathways. J. Neurochem. 2009; 109:1440-51.

36. Bhutia SK, Panda PK, Sinha N, Praharaj PP, Bhol CS, Panigrahi DP, Mahapatra KK, Saha S, Patra S, Mishra SR, Behera BP, Patil S, Maiti TK Plant lectins in cancer therapeutics: Targeting apoptosis and autophagy-dependent cell death. Pharmacol. Res. 2019;144: 8-18.

37. Das A, Narayanam MK, Paul S, Mukhnerjee P, Ghosh S, Dastidar DG, Chakrabarty S, Ganguli A, Basu B, Pal M, Chatterji U, Banerjee SK, Karmakar P, Kumar D, Chakrabarti G. A novel triazole NMK-T-057 induces autophagic cell death in breast cancer cells by inhibiting $\gamma$-secretase-mediated activation of Notch-signaling. J. Biol. Chem. 2019; 294:6733-50.

38. Classen F, Kranz P, Riffkin H, Pompsch M, Wolf A, Göpelt K, Baumann M, Baumann J, Brockmeier U, Metzen E.Autophagy induced by ionizing radiation promotes cell death over survival in human colorectal cancer cells. Exp. Cell Res.2019; 374: 29-37.

39. Fu Z, Cheng $X$, Kuang I, Feng $H$, Chen L, Liang J, Shen $X$, Yuen S, Peng $C$, Shen B, Jin Z, Qiu W. CQ sensitizes human pancreatic cancer cells to gemcitabine through the lysosomal apoptotic pathway via reactive oxygen species. Mol Oncol. 2018; 12.529-44.

40. Elliott IA, Dann AM, Xu S, Kim SS, et al. Lysosome inhibition sensitizes pancreatic cancer to replication stress by aspartate depletion. Proc. Natl. Acad. Sci. U S A. 2019;116: 6842-7.

41. Zhan YY, Chen Y, Zhang Q, Zhuang JJ, Tian M, Chen HZ, Zhang LR, Zhang HK, He JP, Wang WJ, Wu R, Wang Y, Shi C, Yang K, Li AZ, Xin YZ, Li TY, Yang JY, Zheng ZH, Yu CD, Lin SC, Chang C, Huang PQ, Lin T, Wu Q. The orphan nuclear receptor Nur77 regulates LKB1 localization and activates AMPK. Nat. Chem. Biol.2012; 8: 897-904.

42. Cheng L, Zeng G, Liu Z, Zhang B, Cui X, Zhao H, Zheng X, Song G, Kang J, Xia C. Protein kinase $B$ and extracellular signal-regulated kinase contribute to the chondroprotective effect of morroniside on osteoarthritis chondrocytes. J. Cell Mol. Med. 2015; 19:1877-86

43. Beloueche-Babari M, Peak JC, Jackson LE, Tiet MY, Leach MO, Eccles SA. Changes in choline metabolism as potential biomarkers of phospholipase C $\{$ gamma 1 inhibition in human prostate cancer cells. Molecular cancer therapeutics.2009;8:1305-11.

44. Ueda K, Arakawa H \& Nakamura Y. Dual-specificity phosphatase 5 (DUSP5) as a direct transcriptional target of tumor suppressor p53. Oncogene. 2003; 22:5586-91.

45. Maejima $\mathrm{Y}$, Adach $\mathrm{S}$, Morikawa $\mathrm{K}$, Ito $\mathrm{H}$ \& Isobe $\mathrm{M}$. Nitric oxide inhibits myocardial apoptosis by preventing caspase-3 activity via S-nitrosylation. J. Mol. Cell Cardiol. 2005; 38:163-74 
46. Zhang B, Wang F, Dai L, Cai H, Zhan Y, Gang S, Hu T, Xia C, Zhang B. Lentivirus-mediated PLC $\gamma 1$ gene short-hairpin RNA suppresses tumor growth and metastasis of human gastric adenocarcinoma. Oncotarget. 2016;6: 8043-54.

47. Dai L, Zhuang L, Zhang B, Wang F, Chen X, Xia C, Zhang B.DAG/PKC 8 and IP3 $/ \mathrm{Ca}^{2}+/ \mathrm{CaMK}$ II $\beta$ operate in parallel to each other in PLC $\gamma 1$-Driven cell proliferation and migration of human gastric adenocarcinoma cells, through Akt/mTOR/S6 Pathway. Int. J. Mol. Sci. 2015;16: 28510-22.

48. Tam WL, Lu H, Buikhuisen J, Soh BS, Lim E, Reinhardt F, Wu ZJ, Krall JA, Bierie B, Guo W, Chen X, Liu XS, Brown M, Lim B, Weinberg RA. Protein kinase $C$ alpha is a central signaling node and therapeutic target for breast cancer stem cells. Cancer cell. 2013; 24:347-64.

49. Sanduja S, Feng Y, Mathis RA, Sokol ES, Reinhardt F, Halaban R, Gupta PB. AMPK promotes tolerance to Ras pathway inhibition by activating autophagy. Oncogene.2016; 35:5295-303.

50. Maris P, Blomme A, Palacios AP, Costanza B, Bellahcène A, Bianchi E, Gofflot S, Drion P, Trombino GE, Di Valentin E, Cusumano PG, Maweja S, Jerusalem G, Delvenne P, Lifrange E, Castronovo V, Turtoi A. Asporin Is a Fibroblast-Derived TGF- $\beta 1$ Inhibitor and a Tumor Suppressor Associated with Good Prognosis in Breast Cancer. PLoS Med. 2015;12:e1001871.

51. Chen $\mathrm{Q}$, Zhang $\mathrm{B}, \mathrm{Yi} \mathrm{T}$ \& $\mathrm{Xia}_{\mathrm{C}} \mathrm{C}$. Increased apoptosis in human knee osteoarthritis cartilage related to the expression of protein kinase $\mathrm{B}$ and protein kinase Ca in chondrocytes. Folia Histochem. Cytobiol. 2012; 50:137-43.

52. Mukherjee AK, Saviola AJ, Burns PD \& Mackessy SP. Apoptosis induction in human breast cancer (MCF-7) cells by a novel venom l-amino acid oxidase (Rusvinoxidase) is independent of its enzymatic activity and is accompanied by caspase-7 activation and reactive oxygen species production. Apoptosis.2015; 20:1358-72 